\title{
La música per a piano composta per autors castellonencs fins a 1936
}

\author{
ÓsCAR CAmpos Micó (oscar.camposmico@hotmail.com) \\ Conservatori Professional de Castelló
}

\section{El piano en el context musical castellonenc}

La província de Castelló compta amb un interessant i nodrit repertori d'obres per a piano, compost per autors i autores autòctons. Del conjunt de peces pianístiques que formen el referit corpus, les escrites abans de la Guerra Civil de 1936 no han estat a penes difoses o interpretades en recitals públics, ni introduïdes en els programes oficials de conservatoris i escoles de música. Moltes d'aquestes obres reuneixen, no obstant això, una inqüestionable qualitat pianística i compositiva que demostren l'avançat nivell musical d'alguns dels autors i que, per això, mereixen un atent estudi.

Fins ara no mai s'havia abordat una anàlisi detallada de la música per a piano dels nostres autors que permetera visualitzar d'una manera clara l'evolució i la trajectòria dels diferents estils des de la implantació d'aquest instrument a la província de Castelló, a principis del segle XIX. Recentment, han estat publicades diverses biografies ben documentades sobre compositors castellonencs, majoritàriament del segle xx, que fan una referència tangencial a les seues obres pianístiques. Cal citar, en aquest sentit, els treballs publicats d'Emilio Santos Andrés, Rafael Monferrer Guardiola, Vicente Ros, els més recents de Daniel Gil Gimeno, Rosa Solbes i José Manuel Palacio Bover. També cal fer referència obligada a articles de revista escrits per Eduardo Ranch Fuster i per Carlos Pallarés Esclápez.

Entre les causes d'aquest notori desconeixement del repertori per a piano, el qual constitueix una part important de la cultura castellonenca, es troba, en principi, la inestabilitat política espanyola d'aquest període, que a la província de Castelló va desembocar en les Guerres Carlines, amb una forta repercussió en les comarques de l'interior. Després del triomf del liberalisme i convertida la capital de província en un dels baluards del republicanisme espanyol, tots aquells carlins, entre els quals es trobaven bons músics i compositors, es van exiliar a França o van trobar refugi en altres llocs de l'Estat. Una altra important causa de la falta de divulgació del referit repertori va ser l'absència d'un conservatori de música de caràcter oficial a la capital de la província que despertara l'interès i la consciència cap a la música d'àmbit local. Aquesta carència era deguda, principalment, a la relativa proximitat amb València, que posseïa un conservatori de música des de 1879 i amb estudis oficials des de 1911.

No obstant això, la ciutat de Castelló va comptar, des d'aproximadament la segona meitat del segle XIX i principis del xx, amb un creixent ventall d'activitats musicals que

${ }^{1}$ Traducció del Servei de Llengües i Terminologia (UJI). 
va aportar a la capital un dinamisme poc comú, si es té en compte el caràcter rural propi d'una ciutat xicoteta, dedicada bàsicament a activitats agrícoles i artesanals. El moviment musical es va concretar bàsicament en la formació de bandes, com a consequiència de la institucionalització de la música, així com en la constitució d'orquestres, orfeons, grups de cambra i fins i tot companyies líriques que actuarien en actes de diversa índole, promoguts principalment pels teatres de la capital i província, els organismes polítics i religiosos, els casinos i les famílies d'alt poder adquisitiu. Es tractava de formacions constituïdes majoritàriament per músics no professionals, que fomentaven la música per plaer i afició, encara que també és cert que a la província de Castelló va nàixer un nombre gens menyspreable d'instrumentistes i compositors dedicats enterament a la música o amb estudis oficials.

Els músics que van desenvolupar la seua activitat a Castelló es van formar principalment en col-legis dirigits por preveres o en ordes religioses. No obstant això, el primer centre d'ensenyança musical castellonenca del qual tenim constància a través de la premsa no va partir d'iniciativa religiosa. A semblança de la veïna ciutat de València, que comptava amb acadèmies de música des de 1841 (Blasco, 1896: 62), a Castelló es va establir, en 1860, l'acadèmia de música La Lira, dirigida per Juan Bautista Ballester i Francisco González (La Crónica de Castellón, núm. 27, 28-3-1860). No hi ha noves notícies d'aquesta acadèmia després de 1860, encara que és molt probable que arribara a funcionar regularment, ja que en 1868 apareix anunciat en premsa un Método de Solfeo, escrit per Francisco González, un dels directors de l'esmentada acadèmia, possiblement per a l'ús en la mateixa (Crónica castellonense, 2, 21-3-1868). Hi ha indicis suficients per a pensar que el tal Francisco González no era un altre sinó Francisco González Chermá (*1832; †1896), el líder republicà, alcalde de Castelló des de 1868 i tres vegades diputat a Corts durant el Sexenni, director propietari i titular de la Imprenta del Centinela Federal (Viciano i Navarro, 1987: 73) i músic molt actiu dins i fora de la província durant la segona meitat del segle XIX. Va ser professor de violí i també compositor, sent un dels seus alumnes destacats Francisco Cantó Blasco, metge de l'Hospital General de València i des de 1866 íntim amic del guitarrista Francisco Tárrega Eixea (*1852; †1909) (Arte y letras, 19, 15-12-1915).

A més de la referida acadèmia La Lira, la ciutat de Castelló va comptar, en l'últim terç del segle XIX, amb l'acadèmia d'Eugenio Ruiz (Rius, 2002:17) i l'acadèmia de Juanito Bisbal (Tirado, 1995: 12), on s'estudiava música i també ball. Eugenio Ruiz va ser un altre dels músics d'un cert relleu en l'àmbit local. Era cec i tocava el piano al Café de la Perla, situat en aqueix moment en el carrer d'Enmig, si bé també va desenvolupar funcions d'organista a la mateixa ciutat cap a l'any 1883 (Traver, 1918: 52).

Del conjunt de col-legis de primera i segona ensenyança que englobava la ciutat de Castelló en la segona meitat del segle xıx, només s'hi estudiava música i particularment piano en els de caràcter privat, bé dirigits per religiosos o per particulars, en els quals aquestes matèries eren considerades d'adorn. Entre aquests va destacar el Colegio de la Purísima Concepción, de segona ensenyança, dirigit pel prevere Jaime Pachés Andreu i agregat a l'Institut Provincial i a l'Associació de la felicitació sabatina a Maria Immaculada canònicament erigida en l'Església de Santa Clara (La Defensa, 23, 8-71883). Jaime Pachés Andreu (*1829; †1897) va ser junt amb el seu germà Francisco Pachés Andreu, també prevere i mestre de capella de l'església de Santa Maria, un dels principals 
professors i impulsors de la música en l'àmbit local. Va aconseguir dominar diversos instruments com el piano, l'harmònium, la guitarra i especialment el violí i, dotat també d'una excel·lent veu de tenor, cantava assíduament en les funcions religioses de l'església de Santa Clara. Ensenyava diverses matèries musicals al Colegio de la Purísima Concepción, secundat pel seu germà Francisco que impartia específicament classes de piano i violí (Traver, 1918: 58). Entre ambdós van formar la majoria de músics que van exercir com a tals des de finals del segle XIX i principis del xx a Castelló i província. Els preveres Jaime i Francisco Pachés es van fer càrrec igualment de les lliçons de música i de les formacions musicals dels centres assistencials, particularment de la Casa de Beneficència (Revista de Castellón, 12, 16-6-1882) i del Col·legi de l'Hospital (Revista de Castellón, 17, 1-10-1881) durant l'últim terç del segle XIX.

A Castelló, abundaven els col-legis on les classes de música, i particularment les de piano, estaven destinades a xiquetes $i$, en el cas dels religiosos, estaven dirigits per monges adherides a un determinat orde. ${ }^{2}$ Aquests centres religiosos eren el Colegio de Nuestra Señora de la Consolación, on s'impartien classes de solfeig i música en general (Diario de la Plana, 138, 18-6-1898), i el Colegio del Sagrado Corazón de Jesús, dirigit per les Germanes Carmelites de la Caritat, on s'ensenyava música i cant i comptava, així mateix, amb un cor d'alumnes (La verdad, 134, 28-6-1891; El liberal, 605, 2-6-1894). En 1899 va començar a funcionar el Colegio de los Padres Escolapios, on les classes de música eren impartides pel mestre nacional i reverend Francisco Escoín Belenguer $(* 1885 ; \dagger 1954)$ (Revista de Castellón, 44, 31-12-1913). Els col-legis privats, dirigits per particulars, tots per a xiquetes, on es va impartir música des de finals del segle XIX van ser el Colegio de la Virgen del Lidón, on la professora Vicenta Cano impartia solfeig i piano (La defensa, 248, 15-11-1885), el col·legi de la senyora Vicenta Armengot y Vila, que tenia un cor d'alumnes (La alborada, 195, 21-3-1878; Diario de Castellón, 639, 4-6-1878), i el Col-legi de la senyora Vicenta Soriano (La defensa, 95, 27-3-1884).

Ja entrat el segle xx, va haver-hi a Castelló una progressiva proliferació de centres $i$ acadèmies musicals que va culminar amb un període de màxima activitat, coincident amb els anys de la Segona República. Aquest creixent interès per la música va ser degut, en part, a la influència $i$ al reconeixement internacional de Francisco Tàrrega Eixea, qui es va deixar sentir en la vida musical local poc després de la seua mort en 1909. Prova d'això va ser la fundació, en 1916, de l'acadèmia anomenada La Colonia Educativa on s'impartien assignatures d'adorn com ara solfeig i piano (Heraldo de Castellón, 12862, 26-9-1931), sent el professor José García Gómez (*1898; †1958) el responsable d'aquesta última matèria (La provincia nueva, 1900, 27-9-1923). Aquest centre educatiu va arribar a ser considerat, en els anys trenta, com el més important de la província, tant pel nivell

\footnotetext{
${ }^{2}$ La Llei Moyano, de 1857, establia una educació i un currículum obligatòriament diferenciat per a xiquets i xiquetes amb el fi de proporcionar a la dona una educació moral perquè aprenguera a moure's fonamentalment en àmbits privats; aquesta educació tenia prioritat sobre la pròpia instrucció i va repercutir en el rol social femení fins ben entrat el segle xx. Més encara, l'educació de la dona es diferenciava segons fóra dirigida a les classes altes, mitjanes o baixes. Així, a les xiquetes de classe alta, a més de llegir i escriure, se les preparava per a cuinar, cosir, brodar i desenvolupaven aptituds complementàries en geografia, història, música i fins i tot en dibuix i francès. Les xiquetes de classe mitjana patien interessos enfrontats en intentar compaginar educació i la vida laboral i, en les classes més desfavorides, les dones conjuminaven l'activitat laboral pròpia amb el treball del marit fonamentalment (Aguilar, 1997: 504-505).
} 
de preparació del professorat com per les àmplies installacions que permetien impartir un gran nombre d'assignatures.

El Conservatori de Música de Castelló va ser inaugurat, en 1932, a la plaça de l'alcalde Forcada núm. 1, concretament, el 28 de setembre de 1932, en forma de patronat, presidit per José Salvador Ferrer, ${ }^{3}$ comerciant dedicat a l'exportació de la taronja, violinista i pare de la compositora Matilde Salvador i de la violinista Josefina Salvador. El claustre inicial de professors va estar format per Abel Mus, professor de violí i director del Conservatori; Vicente Tárrega - germà del compositor i guitarrista Francisco Tárrega-, professor de violí; Encarnación Mus, M. Concepció Añó i Josefa Gimeno, professores de piano; Pascual Asencio i Manuel Mora, professors de solfeig i Vicente Asencio, professor d'harmonia, estètica i història (Aguilar, 1997: 315). Les primeres audicions d'alumnes del Conservatori de Castelló van tindre lloc a finals de l'any 1932 i primers de 1933 i pràcticament es van limitar a les intervencions de les germanes Josefina i Matilde Salvador, els germans Miguel i Magdalena Llansola, Amparo Mas i Amparo García. Les audicions van consistir en interpretacions solistes o a quatre mans al piano, música de cambra de violí i violoncel amb piano i demostracions de solfeig (República, 448, 21-11-1932).

En 1933 va obrir les portes el Liceo Beethoven, una acadèmia de música que va plantejar una alternativa al Conservatori de Música i va competir amb aquest últim per les subvencions del consistori i la Diputació. El Liceo Beethoven de Castelló va estar dirigit pel professor de piano José García Gómez (Diario de Castellón, 2900, 19-7-1934), qui ja havia impartit classes de música des de molt jove a la Colonia Educativa. L'Escola Municipal de Solfeig va ser una altra de les institucions educatives especialitzades que va funcionar a Castelló en els temps de la Segona República. Aquest establiment municipal va estar dirigit per Julio Sabater Roig fins a 1934 i per Teresa Peláez Gas des d'aquest mateix any (Llibre d'actes de l'Ajuntament, 23-2-1934) i va adquirir un piano de la marca Retter, en 1935, per al desenvolupament de les classes (Llibre d'actes de l'Ajuntament, 13-12-1935). Paral-lelament, a una altra acadèmia de música menys rellevant denominada Academia Tárrega, es van impartir classes de piano i violí durant els anys de la Segona República; l'assignatura de piano estava a càrrec de la professora María Tárrega (Heraldo de Castellón, 12868, 3-10-1931). Finalment, a l'Escola Normal de Mestres, institució fundada en 1900, a Castelló, es van impartir igualment classes de música, les quals van cristal-litzar en la formació d'un Orfeó Normalista, encarregat d'interpretar cants escolars, basats en cançons folklòriques, principalment espanyoles. La formació musical en aquest centre va estar a càrrec de la professora María Sánchez (República, 608, 205-1933 i 609, 22-5-1933).

L'ambient musical castellonenc, pel que a recitals de piano es refereix, va ser prou modest durant el segle xIx i principis del xx, però la situació milloraria considerablement després de la fundació de la Sociedad Filarmónica, en 1923 (Peris i Calduch, 2008: 11). Fins aqueix any, només ens queda constància d'uns pocs recitals de piano, ja que en la majoria dels casos, els espectacles musicals constaven de diversos números diferenciats,

\footnotetext{
${ }^{3}$ Citat com José Salvador per les fonts, el castellonenc José Salvador Ferrer ha estat moltes vegades confós amb el compositor, pianista i pedagog valencià José Salvador Martí (*1874; †1947), sent-li atribuïts, al comerciant castellonenc, els mèrits del valencià, tant en premsa com en diversa bibliografia. (República, 272, 28-4-1932; Aguilar, 1997: 314; Gil, 2007: 101).
} 
en els quals es rellevaven diversos instrumentistes i cantants, duts a terme en institucions públiques, casinos o domicilis particulars.

En la segona meitat del segle XIX, els recitals de piano es van realitzar usualment als dos casinos, destacant entre ells l'executat pel pianista egipci Òscar Camps i Soler en 1876 (Diario de Castellón, 140, 3-1-1876), el realitzat pel capità Voyer, en 1884 (Revista de Castellón, 78, 15-3-1884) o pel pianista i compositor català Enrique Granados (Solbes, 2007: 25).

Dies després de l'obertura del Teatre Principal, en 1894, la companyia que va estar encarregada de l'acte inaugural, va tornar a actuar en un improvisat recital als salons del Casino Antic. En aquesta ocasió, el que fóra director de l'orquestra, José Valls (*1859; $\dagger 1909$ ), va donar un recital de piano i també va acompanyar alguns dels cantants (El liberal, 535, 3-3-1894). Ja en 1905, la premsa es va fer eco del recital del pianista català Joaquín Malats, i va donar a conèixer el currículum del celebrat intèrpret dies abans de la seua actuació al Teatre Principal, que va tindre lloc el 19 d'octubre d'aqueix any (Heraldo de Castellón, 3967, 17-10-1905).

Des de la segona dècada del segle xx, l'entorn pianístic es va veure afavorit per la fundació, en el mes de març de 1923, de l'Associació de Cultura Musical de Borriana i, mesos després, de la Societat Filharmònica de Castelló. L’Associació de Cultura Musical de Borriana va contractar, entre altres concertistes, el pianista polonès Arthur Rubinstein, el qual va oferir un memorable recital de piano al teatre Oberón d'aqueixa ciutat, el 30 de maig de 1923 (Peris i Calduch, 2008: 40). Per la seua banda, la Sociedad Filarmónica de Castellón va presentar recitals d'excel·lents pianistes, entre els que van destacar el realitzat, en 1924, per Arthur Rubinstein, en 1923 i 1926 per Alexandre Brailowsky, en 1924 i 1925 per Emil von Saüer i, en 1927, pel pianista nascut a Vinaròs, Leopoldo Querol.

L'entorn pianístic castellonenc es va veure, així mateix, propiciat des de l'últim terç del segle XIX per la participació de pianistes locals, per mitjà de recitals conjunts o formant grups de cambra, en vetllades literariomusicals. Abans de la inauguració del Teatre Principal, en 1894, els dos casinos i la sala d'actes de l'Institut van ser els escenaris preferentment triats per a aquest tipus d'esdeveniments públics.

També les tertúlies a cases particulars de famílies distingides van impulsar considerablement, des de la dècada de 1880, l'ús del piano i l'ampliació del repertori d'aquest. Entre els pianistes que van participar en les vetllades literariomusicals, actes benèfics als escenaris detallats amb anterioritat a finals del segle XIX, així com en tertúlies familiars, van destacar José Vilaplana, futur president de la Sociedad Filarmónica, i Vicenta Remolar. A banda d'aquests dos intèrprets, caldria esmentar altres pianistes igualment actius en vetllades i actes benèfics a finals del segle XIX i principis del xx, com Joaquín Rocafort (Tirado, 1995: 14), Domingo Segarra (Revista de Castellón, 74, 15-1-1883), Joaquina Segarra ${ }^{4}$ o Pepita Monfort Ortiga (Tirado, 1995: 169).

A més dels pianistes partícips en vetllades i tertúlies a cases particulars, caldria també destacar aquells que van exercir la seua tasca amenitzant els casinos. Tant el Casino Nou

\footnotetext{
${ }^{4}$ La compositora Matilde Salvador, neboda de Joaquina Segarra, afirma que la seua tia tocava molt bé el piano, i inclús va arribar a actuar en un recital que es va celebrar a Castelló a principis del segle xx junt amb Enrique Granados, convidada per ell; va interpretar-hi una sonata de C. Weber (Solbes, 2007: 25).
} 
com el Casino del Cercle d'Artesans, inaugurat al desembre de 1885, van disposar de pianistes encarregats puntualment d'amenitzar les vetllades de vesprada i nit. Francisco Tárrega, qui havia estudiat piano des de l'any 1876 al Conservatori de Madrid, va exercir com a pianista al Casino de Borriana (Rius, 2002: 26) i, anys després, cap a 1882, va ser pianista del Casino Nou de Castelló cobrant sis quinzets diaris. També el Casino del Cercle d'Artesans de Castelló va comptar puntualment amb un pianista anomenat el cec Patuel, que tocava des de la una a les tres de la vesprada i des de la set a les deu de la nit, i cobrava un modest sou (Ribés, 1916: 237).

\section{Aproximació al repertori pianístic d'autors castellonencs}

Els antecedents del repertori pianístic comprenen, en línies generals, totes les obres que van ser compostes per a teclat, sense determinació pels compositors del tipus d'instrument al qual anaven dirigides. A Espanya, les obres compostes en el període referit eren de tecla o per a tecla, i es podien interpretar en instruments de cordes puntejades com el clavecí, l'espineta i el virginal, de cordes fregades com el clavicordi, o de vent com l'òrgan. L'escaló que delimita la música de tecla a les primeres composicions pròpiament pianístiques de finals del segle XVIII el determina l'oberta elecció per part dels compositors clàssics cap al nou instrument.

Les composicions per a teclat més importants, i que constitueixen un verdader antecedent del repertori pianístic que se succeirà posteriorment a la província de Castelló, van ser fruit del prevere Tomás Ciurana Ardiol (*Peníscola, 1762; †Xàtiva, 1829). Tomás Ciurana, sense haver aconseguit ni tan sols una plaça d'organista catedralici, és l'únic compositor castellonenc amb obra exclusivament per a teclat, que presenta una transició de les tècniques compositives del barroc a les pròpies del classicisme primerenc. Sense ser un innovador des del punt de vista estilístic, ${ }^{5}$ les seues obres suposen la baula natural cap a les noves tècniques compositives de concepció harmònica basades en la tonalitat clàssica, sobre les quals reposaran les primeres composicions pianístiques d'altres autors que conformen el corpus d'aquest treball.

Del conjunt de trenta sonates compostes per Tomás Ciurana, dues es troben a l'Arxiu de l'Església Santa Maria de Morella i les vint-i-vuit restants formen part d'un mateix manuscrit - mancat de l'última pàgina - que es troba a l'Arxiu de l'Església Arxiprestal de Vila-real i on només la penúltima de les sonates està datada en 1822. També es troben en el mateix arxiu de Vila-real el Tema con Variaciones, una fuga i un pas del mateix autor. En una d'aquestes sonates de Tomás Ciurana, concretament la número 22, apareix la indicació

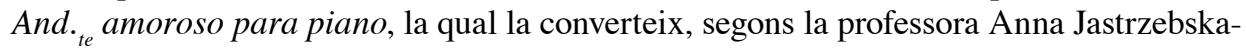
Quinn en la sonata més antiga composta específicament per a piano que es preserva a la Comunitat Valenciana (Ros, 2001: 46). No obstant això, i segons el nostre punt de vista, la referida sonata no aporta la innovació pròpia d'aquest instrument - capaç de crear una varietat de toc i de matisos amb riquesa i potència harmòniques, totalment impossible en els altres instruments de tecla - a causa de la total absència de dinàmiques i signes expressius.

\footnotetext{
${ }_{5}^{5}$ Vicente Rodríguez Monllor (*Ontinyent, 1690 ; †València, 1760) va ser el primer valencià que va escriure obres per a teclat que superaven les antigues tècniques polifòniques i enllaçaven amb les formes tonals que auguraven l'estil clàssic.
} 
Per tant, quant al repertori pianístic d'autors castellonencs es refereix, podem considerar aquesta sonata com la primera obra dirigida, que no pensada, per al piano.

Parlar de les primeres partitures per a piano compostes per autors castellonencs des del primer terç del segle xıx és fer una inevitable referència a l'influx que l'òpera italiana tenia llavors a Europa i, amb especial incidència, a Espanya. La influència de l'italianisme operístic va estar present en pràcticament tots els autors castellonencs que van compondre música per a piano fins ben entrada la dècada de 1860, tant si van ser o no religiosos, com si van romandre a la província o van desenvolupar les seues carreres musicals fora d'aquesta. En aquest sentit, caldria fer una manifesta al·lusió a Valeriano Lacruz Argente, Daniel Sebastián Gabaldá Bel i també, encara que d’una manera més tangencial, als germans Antonio, Vicente i Mateo Pitarch de Fabra, tots ells nascuts a terres castellonenques durant les tres primeres dècades del segle XIX. Mentre la influència italiana en la música per a piano dels esmentats autors no va sobrepassar l'últim terç del segle XIX, el furor italianista i el seu efecte en la composició musical en general es va mantindre a la província de Castelló fins ben entrat el segle xx.

Atenent a trets de sonoritat i d'escriptura, l'obra titulada Sinfonía para Forte Piano, datada en 1837 i composta per Valeriano Lacruz Argente (*Sogorb, 1811; †Sogorb, 1885), pot considerar-se com la primera composició pianística creada per un autor castellonenc i concebuda plenament per a aquest instrument. La Sinfonía para Forte Piano no només incorpora una extensa gamma de dinàmiques que fluctuen entre el $p$ i el ff i abundants signes d'accentuació i expressió, sinó també recursos d'escriptura que requereixen la utilització del pedal dret o de ressonància del piano.

El sorgiment del repertori per a piano a la província de Castelló a partir d'aquesta Sinfonía para Forte Piano, de 1837, va ser relativament anàleg al de les primeres obres verdaderament pianístiques espanyoles escrites a principis del segle XIX de la mà del saragossà Nicolás de Ledesma (*1791; †1883), Pedro Albéniz, de Logronyo (*1795; †1855) o el madrileny Santiago de Masarnau $(* 1805 ; \dagger 1882)$.

No és casual el fet que aquesta primera composició sorgira de la Capella Musical de la Catedral de Sogorb, on sempre va destacar l'alt nivell de preparació dels preveres que van formar-ne part, així com la preocupació per la conservació del patrimoni musical, per l'atenció interpretativa de les obres executades i per la varietat del repertori (Capdepón, 1994: 63), que exigia la composició anual de quatre nadales per a Nadal, quatre més per a la celebració del Corpus, diverses lamentacions i un miserere (Climent, 1992: 215). La Catedral de Sogorb comptava amb una dilatada tradició musical, una de les més antigues d'Espanya que, com apunta José Perpiñán, és possible que tinguera l'origen en temps del Concili Tercer de Toledo, celebrat l'any 589 (La música religiosa en España, 8, 1896).

Aqueixes composicions concebudes pels membres de les capelles que no estaven destinades al culte litúrgic no es guardaven a la catedral. És probable, per tant, que la Sinfonía para Forte Piano de Valeriano Lacruz, arxivada, no obstant això, a la Catedral de Sogorb fóra una donació que ell mateix realitzara a l'arxiu, igual que les seues restants obres instrumentals, localitzades al mateix. ${ }^{6}$ Sobre l'origen d'aquesta interessant composició

\footnotetext{
${ }^{6}$ Aquesta possibilitat ens va ser suggerida per Magín Arroyas Serrano, encarregat de l’Arxiu de la Catedral de Sogorb.
} 
per a piano de caire rossinià no res se'n sap, encara que és possible que fóra escrita per a ús particular de l'autor, encoratjat per les influències italianes i particularment rossinianes que imperaven llavors a València. Fóra quina fóra aqueixa primera relació amb l'estètica rossiniana, l'aportació de Valeriano Lacruz Argente al repertori pianístic castellonenc és una obra pròpia del primer influx italianista, que enllaçarà de manera lògica i fluida amb un italianisme de segona generació, la plasmació del qual al piano serà connexió des de mitjans del segle xıx pel vinarossenc, establert a Madrid, Daniel Sebastián Gabaldá Bel.

El més prolífic, del conjunt de compositors castellonencs que van crear obres per a piano en el període que comprèn el nostre estudi, va ser, sens dubte, Daniel Sebastián Gabaldá Bel (*Vinaròs, 1823; †Madrid, 1898?), qui ha estat objecte d'una recent i interessant biografia escrita per José Manuel Palacio Bover. La seua aportació, inserida en la denominada música de saló, ofereix una doble vessant que comprèn tant les variacions i transcripcions de les òperes italianes d'autors de segona generació, especialment Vincenzo Bellini i Gaetano Donizzeti, com la composició de peces originals, majoritàriament breus, assentades sobre balls de saló vuitcentistes.

L'obra per a piano de Daniel Sebastián Gabaldá Bel representa, en el conjunt del repertori castellonenc del segle XIX, un punt d'inflexió en reprendre l'aportació italianitzant de Valeriano Lacruz Argente i en inaugurar al mateix temps el repertori de ball de saló vuitcentista que tindrà continuïtat en compositors como els germans Pitarch de Fabra, José Segarra Segarra, Bernardo Vives Miralles, Ramón Laymaría Pinella i Florencio Flors Almela.

El repertori de Daniel Sebastián Gabaldá, que comprèn set obres basades en motius d'òperes principalment italianes, unes altres set emmarcades dins del ball de saló vuitcentista i per un mètode pedagògic de piano, va estar majoritàriament concebuda durant el període del romanticisme europeu encara que, igual que el repertori pianístic de la resta dels pianistes espanyols nascuts a principis del segle XIX, no va participar de cap manera de l'estètica ni dels preceptes romàntics.

Sobre les obres de Daniel Gabaldá, inspirades en òpera italiana, hem de fer una distinció entre les fantasies, les quals presenten una important aportació compositiva que mostra les habilitats tècniques i el fecund enginy del vinarossenc, i els arranjaments o transcripcions, que són meres reproduccions per a piano de les obres orquestrals originals. Daniel Gabaldá va ser igualment un compositor summament prolix pel que fa al repertori sustentat en el ball de saló. D'entre les peces que va escriure d'aquest gènere, tres d'aquestes s'ajusten al tipus de dansa basat en motius populars espanyols. Es tracta de tres jotes amb variacions compostes o arreglades d'originals del mateix compositor en 1848, 1853 i 1869 respectivament. Les restants peces de saló escrites per Daniel Gabaldá sobre balls europeus com valsos, xotis o galops són majoritàriament fruit de la col·laboració de l'esmentat autor amb diferents revistes, periòdics i editorials madrilenyes, les quals representaven unes fonts d'ingressos addicionals.

L'autor vinarossenc va treballar, segons pareix, durant prou anys amb especial interès en la confecció d'un Método de Piano, que es revela com l'única obra pedagògica per a

\footnotetext{
${ }^{7}$ Algunes d'aquestes obres no han estat encara localitzades, però en coneixem l'existència a partir d'anuncis exposats en diversos periòdics de l'època.
} 
piano escrita per un castellonenc abans de 1936 i fins i tot fins els nostres dies. Segons les nostres investigacions, aquest mètode, compost per una col·lecció d'exercicis per a piano dividits en dues sèries, no mai es va arribar a publicar. L'aportació de Daniel Sebastián Gabaldá a la pedagogia pianística consisteix en l'original combinació, ja des dels primers exercicis, dels diversos paràmetres tècnics com són la independència de dits o la tècnica de canell amb les extensions. ${ }^{8}$

La pràctica totalitat de les obres pianístiques compostes per autors castellonencs des de la dècada de 1860 fins a final del segle, tret de les fantasies sobre motius operístics del citat Daniel Gabaldá Bel, són formes compositives sustentades en els balls de moda europeus. Les danses utilitzades com a base d'inspiració en les obres esmentades són principalment el vals, la polca, el xotis, l'havanera, els rigodons i la masurca. També trobem altres danses més elaborades, fruit d'una major llibertat formal com la polca-caprici, i d'una original combinació entre dues danses com la polca-masurca.

Així doncs, el piano de saló, adherit a la modalitat dels balls europeus, constitueix una tendència generalitzada entre els compositors castellonencs que van escriure música en la segona meitat del segle XIX i les seues obres pianístiques es manifesten a l'uníson com un fidel reflex de la societat europea del moment.

Són diverses les causes que inclinaran els gustos d'un important sector del públic cap a les danses de saló, amb el consegüent increment i proliferació de les composicions inspirades en aquest gènere. A mesura que avança el segle, l'òpera italiana deixa de ser omnipresent a Espanya i, encara que continua gaudint del favor de certs nuclis burgesos, la balança de preferències s'inclinarà progressivament cap a la sarsuela i els balls de saló. Concretament, ja en l'últim terç del segle es constata a València - ciutat que d'una manera o una altra repercutirà en l'esdevindre d'alguns dels compositors castellonencs d'aquest període - un gradual declivi de l'òpera que cedirà espai a les noves manifestacions exposades amb anterioritat. El moviment cultural de la Renaixença es va deixar sentir tímidament en l'entorn musical quant a la recuperació i revaloració de la tradició i de la consciència musical valenciana, així com en el continu combat dels compositors per a allunyar-se de l'italianisme imperant (Galiano, 1992: 302). Una altra de les causes que van influir de manera decisiva en la renovació dels gustos del públic a Espanya i que va inclinar igualment la balança del costat del repertori de saló, amb una important representació de les danses europees, va ser l'avanç de l'educació musical des de la fundació del Reial Conservatori de Música i Declamació de Maria Cristina, de Madrid, en 1830. El desenvolupament de l'educació en matèria de música va suscitar la importació de partitures dels principals països europeus de sòlida tradició musical, renovant consegüentment els tradicionals repertoris basats en infinites variacions sobre motius operístics principalment de procedència italiana (Gómez, 1984: 72). Finalment, la principal causa des del nostre punt de vista de la implantació de noves formes i hàbits musicals a Espanya des de la segona meitat de segle XIX va estar determinada pels viatges dels pianistes espanyols a l'estranger, principalment a París. Cal recordar que París va

\footnotetext{
${ }^{8}$ Amb la finalitat constatar el grau d'originalitat dels exercicis de Daniel Gabaldá, els hem comparat amb el mètode d'Henri Herz $(* 1803 ; \dagger 1888)$, que va servir d'inspiració al tractat pedagògic de Pedro Albéniz $(* 1795$; $\dagger 1855)$, alumne, aquest últim, d’Henri Herz i professor després del compositor vinarossenc en el Conservatori de Madrid.
} 
ser, amb Viena, un dels nuclis de propagació de l'anomenada música de saló des de poc abans de mitjan de segle (Pratt, 1910: 534).

Si seguim un orde cronològic, són els germans Pitarch de Fabra els primers compositors castellonencs l'obra dels quals per a piano, publicada enterament a París, està inserida totalment en l'anomenada música de saló. L'autoria de les obres per a piano que ens ocupa està compartida pels tres germans, ja que en dues de les tres peces localitzades, concretament Valencia del Cid i L'Espagnole, consten les inicials M.V.A. Pitarch de Fabra, corresponents als noms Mateo, Vicente i Antonio. L'autoria de la tercera de les peces, Les Deux Soeurs, apareix simplement indicada amb els cognoms Pitarch de Fabra i, per tant, deu igualment ser considerada com compartida. Existeix, no obstant això, un important indici que demostra que realment va ser Vicente Pitarch (*Sant Mateu, 1824; †Sagunt, 1910) el principal autor d'aquestes peces i és el fet que l'obra titulada Les Deux Soeurs està constituïda en realitat per dues peces independents, la primera d'aquestes s'anomena Antonia i està dedicada «à ma nièce Antonia Pitarch» i la segona d'aquestes, titulada Marie, porta la dedicatòria «à ma nièce Marie Pitarch». Hem pogut esbrinar a través de Carlos Pallarés Esclápez, rebesnét de Vicente Pitarch, que Antonia i Marie van ser les nebodes de Vicente Pitarch i, per tant, aquest últim, l'autor de la dita obra i possiblement també de les anteriors. ${ }^{9}$

Vicente Pitarch va ser un dels principals partícips de l'acabat de crear Conservatori de Música de València, i açò és un fet que cal subratllar, atès que en cap publicació consultada que fa referència a l'esmentada institució se l'anomena ni una sola vegada. Vicente Pitarch va exercir com a president dels tribunals del Conservatori de Música de València ni més ni menys que en vint-i-set ocasions, durant els cursos escolars de 1883 a 1884, 1886 a 1887 i 1890 a 1891 . Encara que no mai va ser professor del centre, tal vegada per l'avançada edat, el seu nomenament com a president convidat dels tribunals ordinaris testimonia l'admiració i veneració que el claustre de professors del conservatori valencià tributava a aquest músic castellonenc que amb la seua presència dignificava el desenvolupament i el resultat de les avaluacions. Vicente Pitarch va figurar com a president de tribunal de l'assignatura de piano en divuit ocasions en què va avaluar conjuntament amb José María Úbeda, José Valls, Roberto Segura i Manuel Coronado, i també de les assignatures de violí, violoncel, cant i composició junt amb Salvador Giner, Manuel Soriano, Antonio Marco, Andrés Goñi, José Rodríguez i Pedro Varvaro (Actas Oficiales del Conservatorio de Valencia).

També hem d'esmentar Manuel Zaporta Martí (*Morella, 1818; †París, 1902), de qui no hem localitzat cap composició per a piano, però la seua trajectòria biogràfica està íntimament unida a la dels germans Pitarch i conté singularitats d'especial transcendència musical. Tant Manuel Zaporta com Mateo Pitarch són recordats especialment per haver estat els primers professors de piano del compositor francès Emmanuel Chabrier (*1841; $\dagger 1894$ ), a qui van infondre un pronunciat gust pels balls de saló i sobretot pels ritmes i melodies espanyols (Delage, 1999: 31-32), que va desenvolupar enginyosament al llarg

\footnotetext{
${ }^{9}$ Carlos Pallarés Esclápez ens va cedir amablement l'arbre genealògic de la seua família fins a retrocedir als germans Pitarch, resolent moltes de les incògnites que se'ns van presentar durant el procés d'investigació sobre la família Pitarch.
} 
de la seua vida, en la seua obra compositiva, especialment en la seua rapsòdia orquestral composta en 1883 i titulada precisament España.

Continuant en el repertori de saló vuitcentista, José Segarra Segarra (*Castelló, 1816; †Castelló, 1879) és el primer d'una sèrie de compositors castellonencs que van escriure obres per a piano inspirades en balls europeus i que no es van dedicar professionalment al piano. José Segarra va ser un conegut cantant d'òpera i la seua dedicació al piano i a la composició va ser, segons les nostres investigacions, una ocupació secundària encara que no per això sense interès.

L'única obra localitzada de José Segarra, titulada La Heroína, està composta per a piano i és en realitat una polca dedicada «al amigo y muy distinguido pianista Vicente Pitarch». És gràcies a aquesta dedicatòria que la partitura es va conservar entre les composicions de Vicente Pitarch, passant posteriorment a formar part de l'arxiu particular del seu rebesnét Carlos Pallarés Esclápez, qui amablement ens la va cedir per a estudiar-la. Les primeres referències biogràfiques de José Segarra van aparèixer en 1880, tres anys després de la seua defunció, en el Diccionario de Efemérides de Músicos Españoles, de Baltasar Saldoni (Saldoni, 1880: 125-126). De tots els compositors castellonencs del segle xIx tractats en el present estudi, només José Segarra i Daniel Gabaldá apareixen biografiats en el diccionari de Saldoni, la qual cosa mostra la valoració i el reconeixement que ambdós s'havien guanyat al Madrid de la Restauració.

Bernardo Vives Miralles (*Benassal, 1850; †Castelló, 1921) és un dels músics que més inadvertit ha resultat en una part important de la historiografia musical espanyola en general i valenciana en particular, a pesar d'haver produït un important i nodrit repertori pianístic dirigit exclusivament al ball de saló, així com música instrumental i coral diversa. Les úniques notícies sobre Bernardo Vives Miralles són les proporcionades pels preveres Benito Traver García (Traver, 1918: 31-32), Francisco Escoín Belenguer (Escoín, 1919: 98-103) en la segona dècada del segle xx i ja recentment per Pere-Enric Barreda i Edo (Centro de Estudios del Maestrazgo, 38, 5-6-1992).

En el segle XIX era usual, entre els autors espanyols, la composició de peces de saló variades, bé inspirades en balls de moda europeus o en el folklore nacional, les quals eren agrupades habitualment formant una obra major denominada Quadern. El Quadern era, d'aquesta manera, el resultat de la compilació en un mateix àlbum de peces independents entre si del mateix autor, habitualment en diferents tonalitats i estructures formals, com ara rigodons, valsos o masurques - si es tractava d'una col·lecció de danses europees - o bé de zapateados, zorzicos, fandangos i altres balls presos de la tradició popular nacional. Un d'aquests autors va ser Bernardo Vives; les seues peces, inspirades íntegrament en balls de moda europeus, formen part d'un Quadern per a piano, compost cap a 1870, immediatament després d'haver finalitzat l'autor els seus estudis al Conservatori de Madrid.

El violinista i membre d'unes quantes orquestres madrilenyes Ramón Laymaría Pinella (*Castelló, 1856; †Madrid, 1916) va engrossir igualment el repertori pianístic de saló. El principal inconvenient al qual hem hagut de fer front, i que de certa manera ha contribuït a l'escàs coneixement d'aquest peculiar violinista i compositor castellonenc, han estat les diferents variants del seu cognom que tant crítics com biògrafs li han assignat. Algunes d'aquestes variants van respondre a la pròpia voluntat de Ramón 
Laymaría, qui es va donar també a conèixer al Madrid vuitcentista amb els pseudònims de «maestro Laiberi» (El dia, 3162, 17-2-1889) i «señor Lotc-María» (La Iberia, 1177, 22-11-1889). D'altra banda, la premsa i les escasses biografies d'aquest compositor han diversificat encara més la seua identitat i li han atribuït els cognoms de Laimaría i Leymaría, bé per errors ortogràfics dels propis biògrafs, bé per les fonts errònies que van utilitzar.

Distingim dues etapes compositives ben diferenciades que caracteritzen l'obra i l'evolució de l'estil de Ramón Laymaría Pinella i que es van desenvolupar al Madrid de la Restauració. La primera inclou exclusivament polques de saló escrites tant per a orquestra com per a piano durant el període de 1883 a 1889, aproximadament, i la segona alberga la composició de música per a sarsueles breus i sainets compostos en el curt interval, encara que intens, comprés de 1889 a 1892. Ramón Laymaría va escriure en la seua primera etapa compositiva tres polques per a piano denominades Violeta, Las Carolinas i El Submarino Peral. Les denominacions d'aquestes dues últimes guarden relació amb esdeveniments rellevants de l'Espanya de la Restauració.

Florencio Flors Almela (*Vila-real, 1862; $\dagger$ ?) va ser, segons les nostres investigacions, l'últim dels compositors castellonencs vuitcentistes que va escriure música de saló per a piano, ja en el crepuscle del segle XIx. Els èxits, tant pianístics com compositius, del referit autor, van ser paral-lels a la seua vida acadèmica al Conservatori de València. Després de finalitzar els estudis en aquesta institució, i parafrasejant el text de Benito Traver (Traver, 1918: 148), la vida musical de Florencio Flors Almela sembla quedar reduïda a l'ensenyança del piano. En 1891, durant l'últim any de carrera, l'esmentat autor vila-realenc va compondre la seua única obra localitzada fins avui. Es tracta d'una masurca per a piano que porta el suggestiu títol No me mires i que va ser publicada pel Conservatori de València en ocasió del Carnestoltes d'aquell mateix any. ${ }^{10}$

A diferència del segle XIX, en el qual el repertori pianístic castellonenc tirava endavant de manera progressiva i lineal des de la influència de l'òpera italiana en el primer terç del segle fins a la pràctica omnipresència del repertori de saló romàntic cap a 1870, l'arribada de la nova centúria es va caracteritzar especialment per una confluència de nous estils. Aquesta confluència no va representar un fet aïllat pel que fa al repertori pianístic castellonenc, sinó més aviat va respondre a una tendència generalitzada en la composició musical espanyola característica del primer terç del segle xx.

La principal causa d'aquesta amalgama de llenguatges es trobava en la tendència a la modernització de la societat musical espanyola i l'esforç de molts dels compositors per a absorbir els corrents avantguardistes europeus, i utilitzar a marxes forçades tots els llenguatges que a Europa s'havien donat amb anterioritat i, com resultat, es van generar obres impregnades d'estils musicals anacrònics (Marco, 1982: 155). En

\footnotetext{
${ }^{10}$ Tant Ruiz de Lihory com Benito Traver afirmen que Florencio Flors va publicar algunes composicions per a piano. No obstant això, després de rastrejar la premsa especialitzada de l'època, els fons de les biblioteques i els catàlegs, només vam aconseguir localitzar aquesta composició, que, casualment, és l'única que es conserva d'aquest autor a la Biblioteca Nacional d'Espanya i a la Biblioteca Valenciana de Sant Miquel dels Reis. Des d'una altra via d'investigació, el filòleg i escriptor castellonenc Avel-lí Flors Bonet ens va facilitar partitures musicals procedents del seu arxiu particular, entre les quals trobem de nou l'esmentada peça pianística de Florencio Flors.
} 
conseqüència, la vida musical espanyola, fins a 1936, va aglutinar majoritàriament compositors conservadors, continuadors de l'estètica romàntica de saló pròpia de la segona meitat del segle XIX, i altres, en menor quantitat, de tendència progressista que es van valdre de les tendències nacionalistes, impressionistes, neoclàssiques $\mathrm{i}$ d'avantguarda europees.

Igualment existeix, entre els compositors castellonencs que van escriure música per a piano des dels inicis del segle xx, fins a 1936, una diferència d'estils d'acord amb el molt variat paisatge musical espanyol. No obstant això, cal subratllar bé que l'estudi i la classificació per autors que s'exposarà a continuació s'ha confeccionat sobre la base de l'estil i estètica abordats per aquests en les seues obres compostes tant per a piano com per a diverses formacions fins a 1936. Alguns d'aquests autors romandran, després de la Guerra Civil, fidels a la seua estètica abordada des de la seua joventut i altres abraçaran noves tendències, encara que les constants d'estil es mantindran inalterables. Tal com afirma Tomás Marco, l'obra d'un compositor cal contemplar-la en conjunt i sense separacions $i$, en aquest sentit, «la época en que hay que situar a un compositor es aquella en la que empieza a expandirse y alcanza su primera madurez, quedando fijos los grandes rasgos de estilo y las constantes estéticas y técnicas de su lenguaje» (Marco, 1982: 149).

En línies generals, hem de parlar, quant al repertori pianístic castellonenc del primer terç del segle xx, d'un estil majoritàriament conservador que caminarà de la mà, des de finals dels anys vint, d'un naixent nacionalisme impregnat de recursos presos de l'impressionisme francès i que inclou obres caracteritzades per la busca d'una amable evocació sonora.

Dins de l'estil conservador trobem, d'una banda, un retorn a les formes del romanticisme alemany, unit a una perpetuació de la música de saló vuitcentista i, d'un altre, un repertori de matisos popularistes compartit entre un purisme espanyolista protagonitzat pel pasdoble i les danses americanes de moda com el two-step, el foxtrot i el tango. ${ }^{11}$ Són, en aquest sentit, compositors conservadors José Goterris Sanmiguel (*Vila-real, 1873; †Vila-real, 1930), Fulgencio Badal Molés (*La Vall d’Uixó, 1880; †La Vall d’Uixó, 1967), José García Gómez (*Castelló, 1898; †Castelló, 1958), Leopoldo Querol Rosso (*Vinaròs, 1899; †Benicàssim,1985) i Perfecto Artola Prats (*Benassal, 1904; †Màlaga, 1992).

Des de 1914 es produeix a Espanya un allunyament del purisme i una obertura a les avantguardes que cristal-litzarà amb la generació musical del 27 , la qual seguirà amb atenció les idees exposades per José Ortega y Gasset en la seua obra La deshumanización del arte. L'objectiu bàsic que persegueix Ortega a través de les seues reflexions és la creació d'un autèntic llenguatge d'identitat nacional, sustentat en la tradició encara que des de perspectives renovadores.

La modernitat en el repertori pianístic castellonenc va arribar finalment de la mà d'Abel Mus Sanahuja (*Borriana, 1907; †Picanya, 1983) amb la seua obra Escenes d'Infants, composta a París, en 1928, i formada per dotze peces que reviuen escenes costumistes de

\footnotetext{
${ }^{11}$ El repertori pianístic de matisos popularistes no aporta res de nou pel que fa a l'absorció d'avantguardes. Per aquest motiu, la classificació dels autors castellonencs respon principalment a la implicació o no d'aquests en estètiques musicals que suposen una renovació de la composició com a acte creatiu i no com a simple adscripció popularista.
} 
la Borriana de principis de segle. Ací, Abel Mus introdueix elements harmònics, rítmics i d'escriptura prou innovadors - amb relació a la resta de composicions pianístiques dels autors tractats amb anterioritat - però sense abraçar la tècnica i estètica avantguardista europea dels anys vint. Aquests elements apareixen igualment en l'obra Campanas, que una joveníssima Matilde Salvador Segarra (*Castelló, 1918; †València, 2007) va compondre en 1935 sota la tutoria del seu professor i futur marit Vicente Asencio Ruano. Encara que no inserits en l'avantguarda musical espanyola ni perseguint l'ideal estètic propugnat per Ortega y Gasset, la novetat de la producció pianística d'Abel Mus i Matilde Salvador respon més aviat a la feliç combinació dels recursos harmònics tonals i modals i a la subtil creació de plans sonors diferenciats.

\section{BIBLIOGRAFIA}

Aguilar Ródenas, C. (1997): Educació i societat a Castelló al llarg de la II República, Castelló, Diputació de Castelló.

BARREDA I Edo, P.E. (1992): «La música culta a Benassal (Aproximació al costumari benassalenc)», Centro de Estudios del Maestrazgo, 38, abril-junio, 1992.

Blasco Medina, F.J. (1896): La Música en Valencia, Alacant, Imprenta de Sirvent y Sánchez.

CAPDEPón, P. i altres (1994): La música en la Catedral de Segorbe (Siglo XVIII), Castelló, Fundació Dávalos-Fletcher.

Climent Barber, J. (1992): «Las capillas musicales. La transición al barroco», dins Badenes Masó, G. (ed.): Historia de la Música de la Comunidad Valenciana, València, Levante.

Delage, R. (1999): Emmanuel Chabrier, París, Fayard.

Escoín Belenguer, F. (1919): Organografía Musical Castellonense, Castelló, Imprenta J. Barberá.

Galiano Arlandis, A. (1992): «La Renaixença», dins Badenes Masó, G. (ed.): Historia de la Música de la Comunidad Valenciana, València, Levante.

Gil Gimeno, D. (2007): Abel Mus. Una vida dedicada al violín, Borriana, Ajuntament de Borriana.

Gómez Амat, C. (1984): Historia de la música española.5. Siglo XIX, Madrid, Alianza Editorial.

HERz, H. (s.d.): Collection de gammes, exercices et passages pour piano, Barcelona, Vda. de J.M. Llobet.

Marco, T. (1982): Historia de la música española. 6. Siglo XX, Madrid, Alianza editorial.

Monferrer Guardiola, R. (1999): El maestro Perfecto Artola (1904-1992). Una aproximación biográfica, Vila-real, Universidad Nacional de Educación a Distancia.

Palacio Bover, J.M. (2010): Los hermanos Gabaldá. Dos músicos vinarocenses en el siglo XIX, Vinaròs, Associació Cultural «Amics de Vinaròs».

Pallarés Esclápez, C. (2007): «Antonio Pitarch, de San Mateo a Le Puy y viceversa», Cantem, Revista de la Federació de Cors de la Comunitat Valenciana, 17, desembre, 13.

Peris Domínguez, J. i V. Calduch Bellido (2008): Sociedad Filarmónica de Castelló. Memoria de mil conciertos, Castelló, Diputació de Castelló.

Perpiñán Artíguez, J. (1896): «Cronología de los maestros de capilla de la santa iglesia catedral de Segorbe», La música religiosa en España, 8.

Pratt, W.S. (1910): The History of Music, Londres, Sir Isaac Pitman \& Sons.

RANCh Fuster, E. (1947-1948): «Músicos famosos en Valencia. Emmanuel Chabrier estuvo en nuestra ciudad», Valencia Atracción, cLV, desembre de 1947; CLVI, gener de 1948, 8, 115-116.

Ribés SAngüESA, E. (1916): Quadros de Costums Castellonenchs (en serio i en broma), Castelló, Fills de J. Armengot.

Rius, A. (2002): Francisco Tárrega. 1852-2002. Biografía oficial, Vila-real, Ajuntament de Vila-real.

Ros, V. (2001): Obras para tecla de Tomás Ciurana, València, Diputació de València.

Ruíz de Lihory, J. (1903): La música en Valencia. Diccionario Biográfico y Crítico, València, Doménech. 
SAldoni, B. (1880): Diccionario de Efemérides de Músicos Españoles. T. II, Madrid, Imprenta de Pérez Dubrull.

SAntos Andrés, E.J. (1990): El mestre Goterris. Assaig biogràfic,Vila-real, Ajuntament de Vila-real.

Solbes, Rosa (2007): Matilde Salvador. Converses amb una compositora apassionada, València, Tàndem Edicions.

Tirado, J.L. (1995): El Teatro Principal. 1894-1994, Castelló, Ajuntament de Castelló.

Traver García, B. (1918): Los Músicos de la Provincia de Castellón, Vila-real, J. Barberá.

Viciano i NAVARro, P. (1987): «Aproximació a la premsa de l'època isabelina i del sexenni democràtic (1834-1874)», dins 1er Congrés d'Estudis d'Història de la Plana, Castelló, Diputació de Castelló.

\section{BIONOTA}

\section{Oscar Campos Micó}

Nascut a Vila-real en 1965, va finalitzar els estudis superiors de piano i de composició al Conservatori Superior de Música de València amb la qualificació de Matrícula d'Honor, aconseguint també un Premi Extraordinari en l'especialitat de Piano i dues Mencions Honorífiques en les especialitats d'harmonia i contrapunt i fuga. Ha ampliat estudis a l'Escola de Música de Barcelona i a l'École Normale de Musique de París. En l'actualitat realitza una tesi doctoral a l'UJI, dirigida pel doctor Antonio Ripollés Mansilla. 